Bull. Mater. Sci., Vol. 35, No. 4, August 2012, pp. 639-643. (C) Indian Academy of Sciences.

\title{
Microstructure and properties of sintered mullite developed from Indian bauxite
}

\author{
H S TRIPATHI*,A GHOSH, M K HALDER, B MUKHERJEE and H S MAITI \\ Refractories Division, Central Glass \& Ceramic Research Institute (Council of Scientific \& Industrial Research), \\ 196, Raja S. C. Mullick Road, Kolkata 700 032, India
}

MS received 24 March 2011; revised 6 June 2011

\begin{abstract}
Dense mullite aggregates with $72 \% \mathrm{Al}_{2} \mathrm{O}_{3}$ have been synthesized by reaction sintering of two varieties of Indian bauxite and silica sol. The bauxites used are of inferior grade with different levels of accessory impurities such as $\mathrm{Fe}_{2} \mathrm{O}_{3}, \mathrm{TiO}_{2}, \mathrm{CaO}$. The phase and microstructure development of sintered samples were investigated by XRD and SEM. It was found that morphology of the sintered grain is very much dependent on the impurity level. Mullite formed from bauxite-1 with low impurity is mostly equiaxed, whereas mullite developed from bauxite 2 with higher impurity particularly $\mathrm{CaO}$ is needle shaped. Presence of $\mathrm{CaO}$ in bauxite was found to be more detrimental than $\mathrm{TiO}_{2}$ and $\mathrm{Fe}_{2} \mathrm{O}_{3}$.
\end{abstract}

Keywords. Bauxite; mullite; X-ray diffraction; refractory aggregates.

\section{Introduction}

Mullite is a well known refractory material because of several important properties like good mechanical strength, high thermal shock and creep resistance, low thermal conductivity, high-temperature stability, good chemical inertia, high refractoriness, and low thermal expansion coefficient (Kanazaki et al 1985; Rodrigo and Boch 1985; Aksay et al 1991; Schneider et al 2008). Being an extremely rare natural material, mullites are synthetically produced from various alumina and silica through various techniques such as reaction sintering, coprecipitation, sol-gel, hydrothermal and chemical vapour deposition.

Mullite produced from high-purity reagents/precursors is expensive and not techno-economically viable for bulk refractory applications. Normally, cheap and abundantly available natural raw materials are preferred to produce refractory-grade mullite aggregates. Reaction sintering of $\mathrm{Al}_{2} \mathrm{O}_{3}$ and $\mathrm{SiO}_{2}$ bearing materials is a low cost method of mullite formation. The temperature and rate of mullite formation depends on the starting material, their chemical purity and particle size (Rodrigo and Boch 1985; Aksay et al 1991). Typically $\mathrm{Al}_{2} \mathrm{O}_{3}$ and $\mathrm{SiO}_{2}$ containing reactants used for this purpose are clay minerals such as kaolinite, pyrophyllite, sillimanite group of minerals and bauxite (Ghate et al 1973; Zhou et al 1996; Viswabaskaran et al 2004; Ganesh et al 2008). In order to lower the mullitization temperature, it is advantageous to use systems in which aluminum and silicon component are atomically mixed. Admixtures of boehmite, diaspore, gibbsite and refractory grade bauxite with silica

\footnotetext{
*Author for correspondence (hstripathi@cgcri.res.in)
}

have been studied by different investigators (Schneider et al 1982; Zhong 2005).

Good quality refractory grade bauxite potentially should have high refractoriness $\left(\sim 1840^{\circ} \mathrm{C}\right)$ as can be interpreted from the eutectic point in $\mathrm{Al}_{2} \mathrm{O}_{3}-\mathrm{SiO}_{2}$ phase diagram, where these materials were represented on the basis of their two main constituents, $\mathrm{Al}_{2} \mathrm{O}_{3}$ and $\mathrm{SiO}_{2}$ (Osborn and Muan 1960; Aksay and Pask 1975; Caballero et al 1985; Zhong 2005). However, in actual practice their refractoriness under load is low $\left(1450-1550^{\circ} \mathrm{C}\right)$. This behaviour is normally attributed to the presence of a liquid phase in this temperature range due to the presence of impurities like $\mathrm{TiO}_{2}$ and $\mathrm{Fe}_{2} \mathrm{O}_{3}$ in bauxite. Since $\mathrm{TiO}_{2}$ and $\mathrm{Fe}_{2} \mathrm{O}_{3}$ can enter into the mullite structure by solid solution formation, mullite formation from bauxite can reduce the effect of these impurities on the vitreous phase formation.

The objective of the present study is to explore the utilization of Indian bauxite with considerable amount of impurities combined with silica sol to synthesize mullite. Attempts have been made to investigate the effect of chemical composition of bauxite on the densification behaviour, reaction and microstructure development of the mullite aggregates. The composition of the crystalline mullite phase was studied by energy dispersive X-ray (EDX) analysis to correlate the microstructure and properties.

\section{Experimental}

Two varieties of bauxite with different impurity levels collected from Gujarat region of India and colloidal silica suspension containing $40 \mathrm{wt} \%$ particles and a $\mathrm{pH}$ value of 9 obtained from Indian sources. Chemical analyses of these materials were done by standard wet chemical method. 
$0.25 \mathrm{~g}$ solid powdered sample was taken into platinum crucible and the sample was thoroughly mixed with boraxsodium carbonate fusion mixture and melted at around $900^{\circ} \mathrm{C}$ for $1 \mathrm{~h}$. After melting the mass was cooled down and digested with nitric acid to get the solution. Iron and titanium were measured by colorimetric method. Alumina, $\mathrm{CaO}$ and $\mathrm{MgO}$ were determined by complexometric method using EDTA solution. $\mathrm{Na}_{2} \mathrm{O}$ and $\mathrm{K}_{2} \mathrm{O}$ were measured by flame photometry using hydrofluoric acid and perchloric acid digested bauxite solution. $\mathrm{SiO}_{2}$ was measured by gravimetric method.

Bauxite ores were crushed and dry milled to pass through 100 mesh sieve. These powders and silica sol were mixed according to the stoichiometric mullite composition i.e. with a mole ratio of $\mathrm{Al}_{2} \mathrm{O}_{3}$ to $\mathrm{SiO}_{2}, 3: 2$. Batch prepared using bauxite- 1 was designated as $\mathrm{M}-1$ and that of bauxite- 2 as $\mathrm{M}-2$. Batch materials were attrition milled in a zirconia pot with zirconia ball in isopropanol medium for $2 \mathrm{~h}$. The slurry thus obtained was dried at $40^{\circ} \mathrm{C}$ for $24 \mathrm{~h}$ and passed through 100 mesh sieve to get the desired powder. Powdered samples thus prepared were heat treated at various temperatures $\left(850-1250^{\circ} \mathrm{C}\right)$ at normal atmospheric condition and the resultant crystalline phases were identified by X-ray diffraction.

For the densification study, batch powders were mixed with 5\% (W/V) PVA solution as binder and uniaxially pressed at $100 \mathrm{MPa}$ pressure into pellets of $2.5 \mathrm{~cm}$ dia and $1 \mathrm{~cm}$ height. These pellets were then dried at $110 \pm 5^{\circ} \mathrm{C}$ and sintered in the temperature range $1500-1650^{\circ} \mathrm{C}$. The heat treatment was performed in a programmer-controlled electric furnace. Heating rate was maintained at $5^{\circ} \mathrm{C} / \mathrm{min}$ up to $1000^{\circ} \mathrm{C}$ and then $3^{\circ} \mathrm{C} / \mathrm{min}$ up to final temperature with a $2 \mathrm{~h}$ soaking at peak temperature. Sintered specimens were characterized in terms of bulk density, apparent porosity, phase composition and microstructure. The bulk density and apparent porosity of the sintered samples were measured by water displacement method using Archimedes' principle.

Phase identification was done by X-ray diffraction technique. The diffraction patterns of the finely powdered samples were obtained in a Philips X-ray diffractometer (Model PW 1730) using nickel filtered $\mathrm{Cu}-\mathrm{K} \alpha$ radiation and recorded over a Braggs' angle $(2 \theta)$ range of $10-70^{\circ}$. Microstructure evaluation of the sintered compacts was done by scanning electron microscopy (Make Stereoscan, Model LEO's 430i) using sputtered gold coating on the polished surface after thermal etching. Elemental analysis of the mullite grains was done by EDX technique using carbon coated sintered polished samples.

\section{Results and discussion}

\subsection{Raw materials}

The chemical analysis (loss free basis) of two varieties of bauxites is shown in table 1. Chemical composition indicates that they are impure in nature and there is a wide di- fference in chemical composition between them. Bauxite- 1 is relatively purer with $\mathrm{Al}_{2} \mathrm{O}_{3}$ content of $84.58 \%$ compared to that of bauxite- 2 which is $79.53 \%$. $\mathrm{TiO}_{2}$ content of both the bauxites was nearly the same. However, the main impurity $\mathrm{Fe}_{2} \mathrm{O}_{3}$ in bauxite-2 is as high as $6.90 \%$ compared to $5.01 \%$ in bauxite- 1 . $\mathrm{CaO}$ content $(2.44 \%)$ is also significantly higher in bauxite-2, compared to that of bauxite- 1 which is $0.81 \%$.

X-ray diffraction patterns of both the bauxites are similar as can be seen in figure 1. Phase analysis study indicates that the major crystalline phase is gibbsite (PDF No 15-0776) with a small amount of boehmite (PDF No 21-1307). Both the bauxites used in this study are gibbsitic in nature.

\subsection{Reaction}

X-ray diffractogram of the batch materials $\mathrm{M}-1$ and $\mathrm{M}-2$ heat treated at different temperatures have been depicted in figures 2 and 3. From figure 2 it was found that for bauxite-1, there was no mullite formation up to $950^{\circ} \mathrm{C}$ with silica sol and mullite peaks completely absent in the diffractogram. At $1050^{\circ} \mathrm{C}$ the initial peaks of mullite (PDF No 15-0776) appear and the nature of the peaks show that the initial mullitization has started. At $1150^{\circ} \mathrm{C}$ there is improvement in mullitization and stronger peaks of mullite are clearly visible. The crystallinity and extent of mullitization significantly improve with increase in temperature and at $1250^{\circ} \mathrm{C}$ mullite is the

Table 1. Chemical analysis of raw bauxites (loss free basis).

\begin{tabular}{lcc}
\hline Constituents (wt $\%)$ & Bauxite-1 & Bauxite-2 \\
\hline $\mathrm{Al}_{2} \mathrm{O}_{3}$ & 84.58 & 79.53 \\
$\mathrm{SiO}_{2}$ & 5.08 & 6.54 \\
$\mathrm{TiO}_{2}$ & 4.52 & 4.58 \\
$\mathrm{Fe}_{2} \mathrm{O}_{3}$ & 5.01 & 6.90 \\
$\mathrm{CaO}$ & 0.81 & 2.44 \\
\hline
\end{tabular}

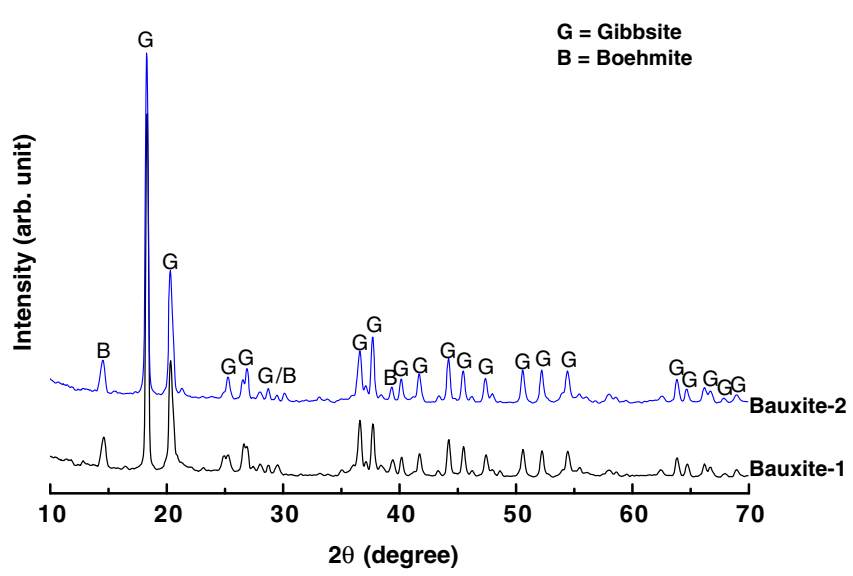

Figure 1. X-ray diffraction patterns of bauxites-1 and 2. 
only visible phase in the diffractogram and corundum phase (PDF No 46-1212) disappears almost completely.

In case of bauxite-2 (figure 3 ), the phase developments take a different path. Up to $1050^{\circ} \mathrm{C}$, there is absolutely no trace of mullite, only corundum peaks (PDF No 46-1212) are visible. At $1150^{\circ} \mathrm{C}$, mullite peaks appear. Even at $1250^{\circ} \mathrm{C}$, corundum peaks do not disappear completely-unlike in case of bauxite-1. Although, the $\mathrm{Al}_{2} \mathrm{O}_{3} / \mathrm{SiO}_{2}$ molar ratio is $3: 2$, both corundum and mullite phases exist side by side at $1250^{\circ} \mathrm{C}$. Bauxite- 2 contains higher amount of impurities particularly alkaline earth oxide $(\mathrm{CaO})$, which forms vitreous phase by reacting with silica. This in turn reduces the availability of silica for mullite formation. This is the main reason of existence of free corundum peak in the X-ray diffractogram at higher temperatures. In both the cases, bauxite first dehydrated to different alumina phases, followed by reaction with the $\mathrm{SiO}_{2}$ component forming mullite.

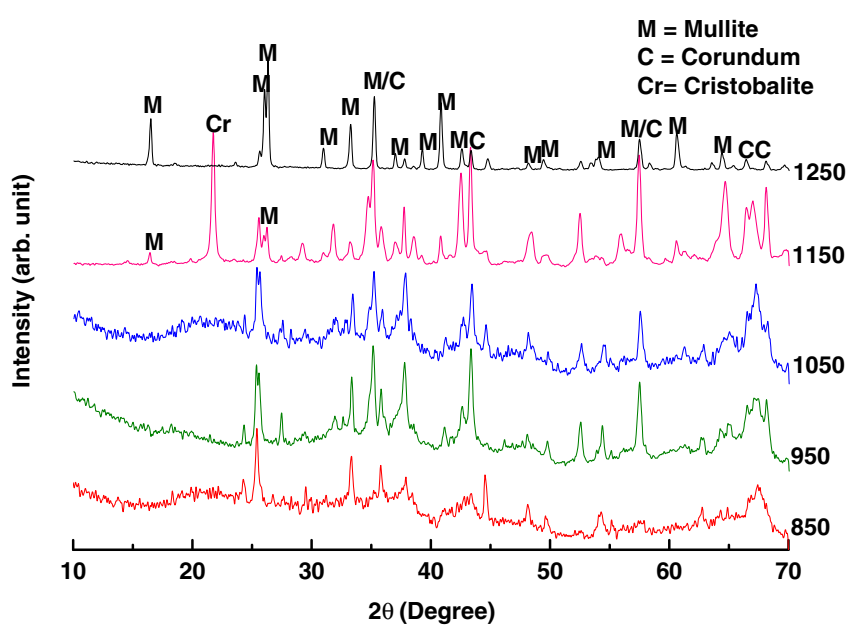

Figure 2. X-ray diffraction pattern of bauxite-1 and silica sol heated to different temperatures.

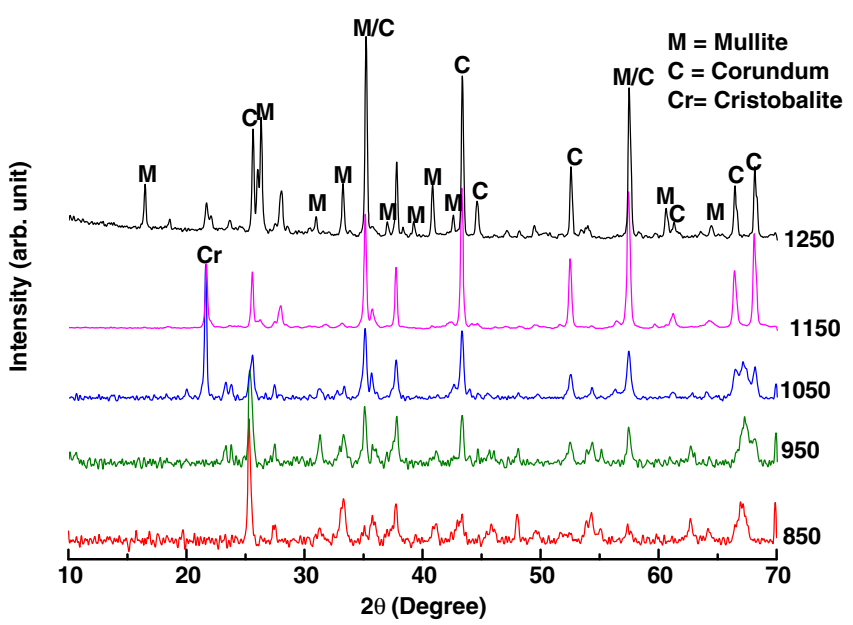

Figure 3. X-ray diffraction pattern of bauxite-2 and silica sol heated to different temperatures.

\subsection{Densification}

Densification is an important part of any ceramic forming process. Variation of bulk density and apparent porosity of the samples with sintering temperature is shown in figure 4.

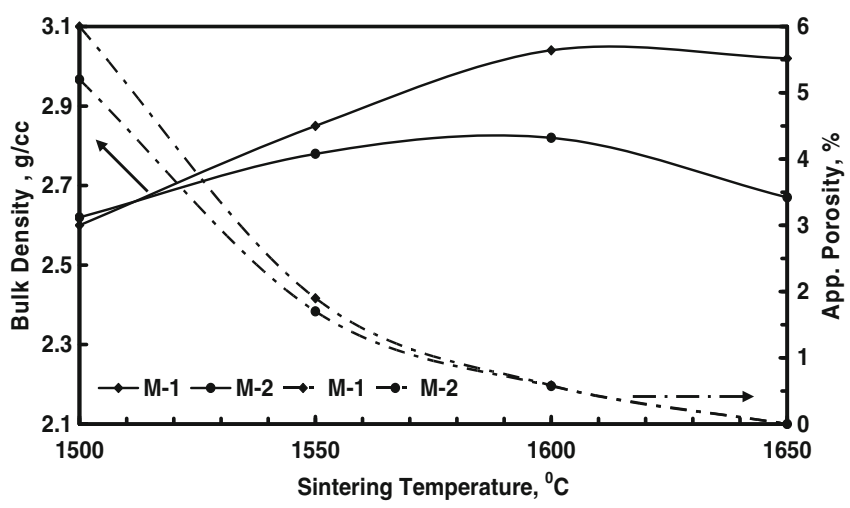

Figure 4. Variation of bulk density and apparent porosity with sintering temperature for $\mathrm{M}-1$ and $\mathrm{M}-2$.
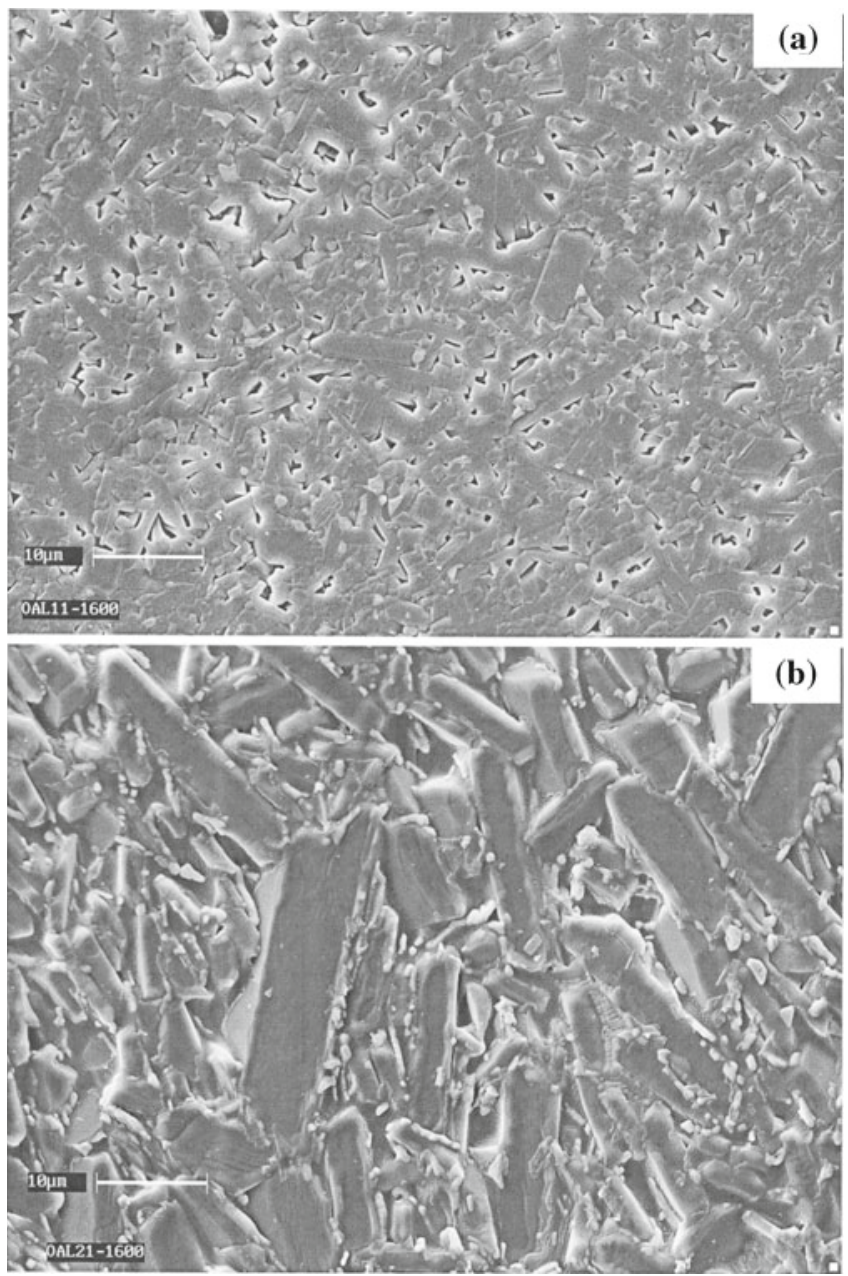

Figure 5. Scanning electron micrograph of mullite aggregates developed from bauxite and silica sol: (a) bauxite-1 and (b) bauxite- 2 . 
It was found that the bulk density gradually increases with sintering temperature up to $1600^{\circ} \mathrm{C}$ followed by decrease in density at $1650^{\circ} \mathrm{C}$. Gradual removal of open pores with an increase in sintering temperature is the reason for higher densification. Formation of higher amount of low density glass at $1650^{\circ} \mathrm{C}$ is the main reason for density reduction at $1650^{\circ} \mathrm{C}$. It was found that M-2 sample always exhibits lower density (except $1500^{\circ} \mathrm{C}$ ) than that of $\mathrm{M}-1$. Presence of higher amount of impurities, particularly $\mathrm{CaO}$, is responsible for the formation of higher amount of vitreous phase thereby reducing the bulk density (Aramaki and Roy 1959; Gentile and Foster 1963; Sacks and Pask 1982). The highest density achieved by $\mathrm{M}-1$ sample at $1600^{\circ} \mathrm{C}$ is $3.02 \mathrm{~g} / \mathrm{cc}$ which is much higher than that of M-2 sample $(2 \cdot 80 \mathrm{~g} / \mathrm{cc})$. True densities of M-1 and

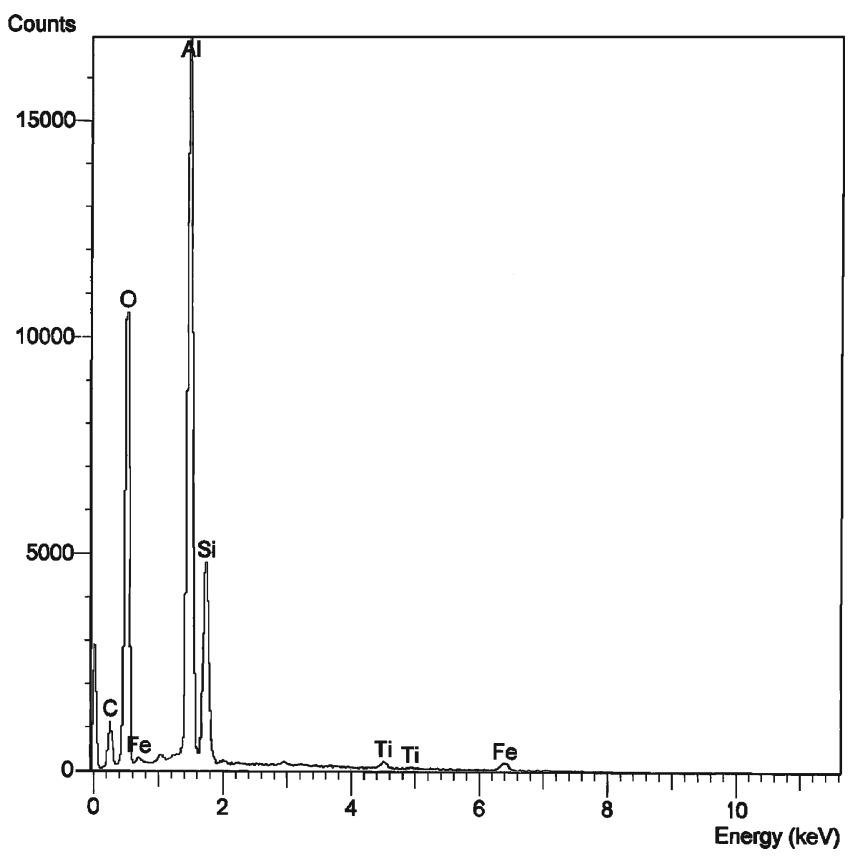

Figure 6. EDX spectra of mullite grain of M-1.

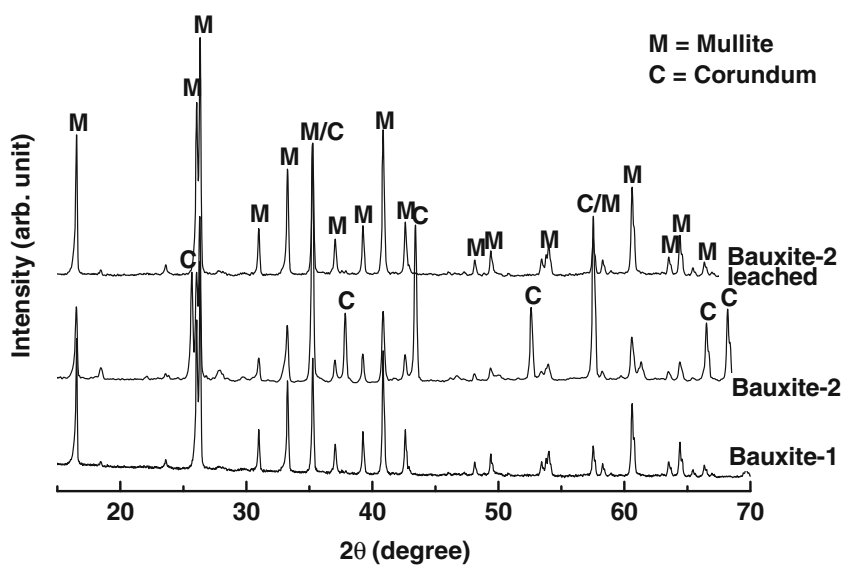

Figure 7. XRD pattern of mullite developed at $1600^{\circ} \mathrm{C}$ from batch composition using silica sol and bauxite-1, bauxite- 2 and acid leached bauxite- 2 .
M-2 samples are 3.05 g/cc and $2.85 \mathrm{~g} / \mathrm{cc}$, respectively. These values are much lower than that of pure mullite $(3.16 \mathrm{~g} / \mathrm{cc})$. Lower true density of both samples indicates the presence of low density glassy phases.

\subsection{Microstructure}

Scanning electron photomicrographs of the sintered mullite developed from bauxite- 1 and bauxite- 2 at $1600^{\circ} \mathrm{C}$ are shown in figures 5(A)-(B). In case of bauxite-1, the microstructure is uniform and more compact with a smaller grain size. Mullite grains are acicular in nature but the aspect ratio is less. This indicates that relatively lower amount of liquid phase has been formed. In case of bauxite-2, the microstructure is strongly heterogeneous and very large grains of mullite are present in the matrix. The corners of grains are also rounded. These indicate the formation of liquid phase which is responsible for uneven growth of mullite grains. Some exaggerated grain growth can also be noticed. EDX pattern of the mullite developed from both the bauxite using silica sol are similar as shown in figure 6. Quantitative analysis indicates that mullite formed is stoichiometric in nature. Solid solubility of $\mathrm{Fe}_{2} \mathrm{O}_{3}$ and $\mathrm{TiO}_{2}$ in mullite developed from bauxite-1 varies from $2.58-4.5 \mathrm{wt} \%$ and $1.76-2.23 \mathrm{wt} \%$, respectively. These values are little lower than the solid solubility of $\mathrm{Fe}_{2} \mathrm{O}_{3}$ and $\mathrm{TiO}_{2}$ in mullite developed from bauxite-2, which are 3.38-5.19 wt\% and 2.18-3.06 wt\%, respectively Earlier investigators also found that $\mathrm{TiO}_{2}$ and $\mathrm{Fe}_{2} \mathrm{O}_{3}$ enter into the mullite structure by solid solution formation (Baudin and Moya 1984; Tripathi and Banerjee 1998; Murthy and Hummel 1960).

In figure 7, X-ray diffractogram of mullite samples developed from bauxites at a temperature of $1600^{\circ} \mathrm{C}$ have been depicted. It can be seen that the only crystalline phase present in the sintered sample developed from bauxite- 1 is mullite, whereas in case of bauxite- 2 it contains considerable amount of corundum phase. The differences in the phase assemblages

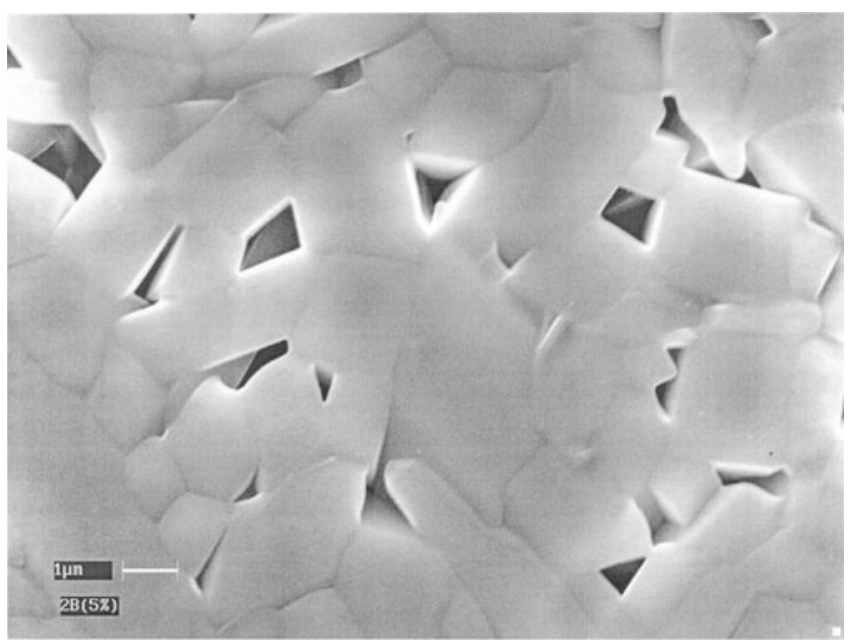

Figure 8. SEM photomicrograph of mullite developed from leached bauxite- 2 and silica sol at $1600^{\circ} \mathrm{C}$. 
can be clearly seen from the diffractogram as discussed earlier. Since bauxite- 2 contains higher amount of $\mathrm{CaO}$, some amount of silica is consumed to form the glassy phase leading to the formation of free corundum along with mullite. This is also responsible for the non-uniform microstructure with exaggerated grain growth of mullite-2 (Hong and Kim 2001).

Bauxite-2 reacted with dilute $\mathrm{HCl}(2 \mathrm{~N})$ to remove considerable amount of $\mathrm{CaO}(90 \%)$. This leached bauxite and silica sol were subsequently used to develop sintered mullite at $1600^{\circ} \mathrm{C}$ as described earlier. SEM photomicrograph of the mullite sample developed at $1600^{\circ} \mathrm{C}$ is shown in figure 8 . Compact microstructure with equiaxed grain indicates much lower amount of glass formation. XRD pattern (figure 7) shows the presence of mullite as the only crystalline phase without any corundum phase. From this study, it can be confirmed that unlike $\mathrm{Fe}_{2} \mathrm{O}_{3}$ and $\mathrm{TiO}_{2}, \mathrm{CaO}$ is more harmful for the development of dense mullite aggregates from bauxites.

\section{Conclusions}

Dense mullite aggregates were synthesized by reaction sintering of Indian bauxite with silica sol. It was found that mullite formation starts in the temperature range $1050-1150^{\circ} \mathrm{C}$. Microstructure and morphology of mullite grain is very much dependent on the impurity level of bauxite. Microstructure of mullite developed from bauxite- 1 is compact with uniform grain size and lower amount of glassy phase whereas mullite developed from bauxite-2 is non-uniform with bigger grain size and higher amount of glassy phase. Some exaggerated grain growth is also observed. $\mathrm{CaO}$ in bauxite is more harmful than $\mathrm{Fe}_{2} \mathrm{O}_{3}$ and $\mathrm{TiO}_{2}$. Considerable amount of $\mathrm{Fe}_{2} \mathrm{O}_{3}$ and $\mathrm{TiO}_{2}$ enters into the mullite structure by solid solution formation. Presence of higher amount of $\mathrm{CaO}$ in bauxite- 2 is responsible for non-uniform microstructure with higher amount of glassy phase and exaggerated grain growth.

\section{Acknowledgement}

We thank the Steel Development Fund, Ministry of Steel, Govt. of India, for providing financial support for this work.

\section{References}

Aksay I A and Pask J A 1975 J. Am. Ceram. Soc. 58507

Aksay I A, Dabbs D M and Sarikaya M $1991 \mathrm{~J}$. Am. Ceram. Soc. $\mathbf{7 4} 2343$

Aramaki S and Roy R 1959 J. Am. Ceram. Soc. 42644

Baudin C and Moya J S 1984 J. Am. Ceram. Soc. 67 C134

Caballero A, Valle F J A and Castillo S 1985 Ceram. Int. 1145

Ganesh I, Sundararajan G and Ferreira J M F 2008 J. Am. Ceram. Soc. 912464

Gentile A L and Foster W R 1963 J. Am. Ceram. Soc. 4674

Ghate B B, Hasselman D P H and Spriggs R M 1973 Am. Ceram. Soc. Bull. 61670

Hong S H and Kim D Y 2001 J. Am. Ceram. Soc. 841597

Kanazaki S, Tabata H, Kumazawa T and Ohta S 1985 J. Am. Ceram. Soc. 68 C6

Murthy M K and Hummel F A 1960 J. Am. Ceram. Soc. 43267

Osborn E F and Muan A 1960 Phase equilibrium diagram in oxide systems (Columbus, OH: American Ceramic Society)

Rodrigo P D D and Boch P 1985 Int. J. High-Technol. Ceram. 13

Sacks M D and Pask J A 1982 J. Am. Ceram. Soc. 6565

Schneider H, Seitert-Kraus U and Majdic A 1982 Am. Ceram. Soc. Bull. 61741

Schneider H, Schreuer J and Hildmann B 2008 J. Eur. Ceram. Soc. 28329

Tripathi H S and Banerjee G 1998 J. Eur. Ceram. Soc. 182081

Viswabaskaran V, Gnanam F D and Balasubramanian M 2004 Appl. Clay Sci. 2529

Zhong X 2005 Am. Ceram. Soc. Bull. 849101

Zhou M, Ferreira J M F, Fonseca A T and Baptista J L 1996 J. Am. Ceram. Soc. 791756 